\title{
Cuento
}

\section{Lo Vemos Mañana *}

See it Tomorrow

Joel Joseph Gonzales-Mendieta ${ }^{1}$

*Primer Puesto. I Juegos Florales Estudiantiles de la Red Peruana Estudiantil de Medicina (REPEM) y Asociación Peruana de Facultades de medicina (ASPEFAM, diciembre de 2019).

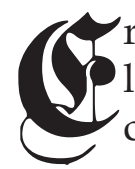

ra un día como cualquier otro, y una larga jornada de trabajo recién había comenzado para Don Nicolás; quien, peinando canas, ya se encontraba en su puesto y orquestando a los empleados de su taller manufacturero.

Poco tiempo había transcurrido, cuando un inusual cansancio se fue apoderando de sus labores y cada vez se hacía más difícil combatir este inusitado malestar con la diligencia y entusiasmo que siempre lo caracterizaron.

De lento inicio, pero progresivo avance, la debilidad que ahora recorría sus extremidades se iba haciendo cada vez más evidente. Aunque no quiso prestarle mayor importancia en un inicio, a medida que las horas transcurrían, estos persistentes síntomas lo llevaron a tomar la severa decisión de cesar toda actividad.

Fue entonces cuando, aún faltando mucho para la hora de descanso, pero con una sensación de no poder continuar, se dirigió hacia sus trabajadores y les indicó que habían terminado por aquel día.

Estudiante de medicina. Facultad de Medicina, Universidad Peruana Cayetano Heredia, Lima, Perú.
Con una palidez de ultratumba, se retiró recibiendo uno que otro "Hágase ver, patrón. Lo veo mañana...", mientras se percataba de las miradas de confusión y preocupación que lo acechaban; lo cual lo llevo a replantearse sobre la magnitud de la situación que lo acosaba.

Manteniendo aún un aire de escepticismo sobre su condición, realizó una llamada para pedir transporte, pues su rumbo ya había sido trazado casi automáticamente tras salir del taller: el consultorio de su médico de cabecera. Pocos minutos después, un vehículo apareció para llevarlo a su destino que no estaba sino muy alejado de su ubicación y, aunque en otros tiempos podría haber ido a pie, sintió que le faltarían piernas para poder realizar tal hazaña en esta ocasión.

Como es casi costumbre, el taxista trato de entablar una coloquial conversación sobre la situación actual del país. Sin embargo, aunque las acandiladas aseveraciones del conductor sobre las últimas políticas de salud resonaban en las paredes del pequeño vehículo, Don Nicolás se abstuvo de realizar algún comentario o siquiera ejecutar algún ademán, pues una recalcitrante astenia ahora invadía su cuerpo.

Durante el viaje, lo único que podía pensar era en todo el trabajo que tendría que hacer al día 
siguiente para compensar su prematura salida; además de los otros quehaceres del hogar, como las compras para la semana y el alimento para sus amadas mascotas.

Ya casi habían llegado a su destino y el conductor aún se encontraba enfrascado en su verborrea médico-política. Cuando por fin el vehículo se detuvo, y se realizó la transacción correspondiente, el conductor se despidió diciendo: "No se olvide de ver la conferencia de mañana"; a lo cual, Don Nicolás, esbozó una ligera sonrisa en respuesta y continuó su camino.

El tramo que ahora lo separaba del consultorio era efímero en comparación a todo lo que ya había recorrido; sin embargo, el malestar que lo iba mermando no le dio tregua alguna e hizo que aquellos últimos pasos pareciesen eternos. Finalmente, se encontró a las puertas de aquella morada que significaría el fin de sus problemas. Al ver que no había algún otro paciente esperando, se invitó a pasar a sí mismo e ingreso solo para encontrarse con un escenario ajetreado y a su médico de cabecera como fuente de tal entropía.

Cuando el médico se percató de su inadvertida visita, sin dejar de organizar sus papeles y alistándose para salir, saludó a su consuetudinario paciente: "Qué tal, Don Nico!, ¿En qué puedo ayudarlo?". Por algún motivo, aquella situación evocó una sensación de desesperanza, en lugar de alivio en Don Nicolás.

Brevemente, le expuso sus mitigantes síntomas a aquel apurado médico que tenia en frente. Probablemente, una emergencia habría surgido para justificar tal comportamiento pues, pese a que escuchaba los descargos de su paciente, continuó alistando todo para su impostergable huida.
Con la confianza de conocer la condición de su paciente de toda la vida y con un asunto urgente que atender, le respondió: "No se preocupe, Don Nico. Qué le parece si lo vemos mañana". Aquella fue una respuesta agridulce que no merecía la proeza que significó el trayecto de venir a verlo. Mientras Don Nicolás salía del consultorio, raudamente, su contraparte cerraba la puerta con llave y se desvanecía de la escena.

Estos últimos acontecimientos fortalecieron la teoría de que lo que fuese que lo aquejaba no podría ser algo tan grave y su procrastinación quizás no sería tamaño pecado. Pese a este pensamiento, Don Nicolás aún refunfuñaba para sí mismo: "Qué le costaba tomarme, aunque sea, la presión".

Tras considerarlo por un momento, pensó en ir a casa a dar por terminada su travesía, pero también apareció en su mente la imagen de su esposa; a quién, finalmente, decidió llamar antes de realizar cualquier último movimiento. Como era de esperarse, el regaño y preocupación que ella manifestó fueron motivo suficiente para que decidiese buscar una segunda opinión. Por fortuna, cerca se encontraba un hospital que era aclamado como uno de los mejores que el Estado había proveído.

Esta vez, con total serenidad, o quizás con una endeblez absoluta, explicó sus síntomas a un médico desconocido para él, pero que lucía impertérrito y presto a realizar cualquier acción con tal de llevar a cabo su imprescindible labor. Con una ejecución protocolar, procedió a realizar la auscultación tras la anamnesis presentada. Al mismo tiempo, se dibujaba una ligera expresión de sospecha en su semblante, por lo cual decidió tomar el estetoscopio y dirigir su atención hacia los sonidos cardiacos. Tras realizar dicha acción, miró al vació un par 
de segundos mientras mostraba un rostro de desconcierto.

Con una encomiable celeridad, llamó a las enfermeras y pidió que derivasen al resto de sus pacientes, que preparasen una camilla y todo el instrumental necesario para la operación.

El, ahora, alarmado médico le pidió a Don Nicolás que permaneciese sentado mientras él conseguía los papeles necesarios para internarlo. Ante tan radical cambio de ambiente, aunque débil, se mostraba genuinamente perplejo y pedía una explicación de lo que estaba sucediendo; a lo que el médico respondió: "¡Señor, usted se está muriendo! Debemos intervenirlo de emergencia".

Los siguientes acontecimientos fueron momentos de alta tensión que terminaron en un quirófano y en la consecuente implantación de un pequeño dispositivo del cual alguna vez había oído hablar, pero nunca pensó depender para poder sobrevivir: un marcapasos cardiaco. Al día siguiente, despertó en una habitación de aquel afamado hospital, junto a su esposa, y encaminado hacia su recuperación. Aún en un estado de letargo, casi no podía creer las palabras del médico cuando le explicaba que haber soportado tanto tiempo en ese estado fue algo inaudito; y si hubiera llevado cualquier otro estilo de vida menos saludable, probablemente no estarían teniendo esa conversación.

Después de realizar el papeleo correspondiente, pudo regresar a sus aposentos para un merecido descanso tras lo que había sido la mayor odisea de su vida. Grande fue el asombro que sintió al ser recibido por sus familiares y amigos en medio de abrazos y lágrimas, pues es indescriptible el sentimiento de angustia y el nudo que se forma en la garganta ante la posibilidad de no volver a ver a algún ser querido.

Después de la algarabía del reencuentro, y con un espíritu renovado, se tomó un momento a solas para meditar acerca de los eventos que habían marcado, lo que él consideraba, un nuevo inicio en su vida; y lo que habría pasado si hubiera tomado cualquier otra decisión aquel día.

Fue entonces que recordó a aquel trabajador, conductor y médico de cabecera que le hicieron referencia a un día al cual pudo no haber llegado nunca de no ser por aquellas miradas de conmoción, aquella llamada a su esposa o el temple de aquel médico que, finalmente, terminaron salvándole la vida.

Animado por tal reflexión, decidió sintonizar la conferencia que le mencionó aquel conductor tan parlanchín. Las sorpresas no pararon de llegar; pues, nuevamente, fue tal su expresión al ver a nada más ni menos que su médico de cabecera dando un discurso acerca de la importancia de la relación médico-paciente en televisión.

Correspondencia:

joel.gonzales@upch.pe

FECHA DE RECEPCIÓN: 30-01-2020.

FECHA DE ACEPTACIÓN: 30-05-2020 